\title{
INFLUÊNCIA DA CARGA ORGÂNICA NO DESEMPENHO DE REATORES DE LEITO MÓVEL COM BIOFILME PREENCHIDOS COM DIFERENTES MATERIAIS SUPORTE
}

\author{
J. P. BASSIN ${ }^{1}$, I. N. DIAS ${ }^{1}$, Y. LARANJEIRA ${ }^{2}$, M. DEZOTTI $^{1}$ \\ ${ }^{1}$ Universidade Federal do Rio de Janeiro, Programa de Engenharia Química \\ ${ }^{2}$ Universidade Federal do Rio de Janeiro, Instituto de Química \\ E-mail para contato: jbassin@peq.coppe.ufrj.br; jp@ufrj.br
}

\begin{abstract}
RESUMO - O tratamento de uma água residuária com alta concentração de matéria orgânica foi investigado em dois reatores de leito móvel com biofilme $\left(\mathrm{MBBR}_{1} \mathrm{e}\right.$ $\mathrm{MBBR}_{2}$ ). O MBBR 1 e o $\mathrm{MBBR}_{2}$ foram preenchidos, respectivamente, com os suportes Kaldnes K1 e Mutag Biochip. A área superficial para o crescimento do biofilme foi a mesma para os dois reatores. A carga orgânica superficial foi aumentada de 3,2 a 12,8 $\mathrm{g}$ $\mathrm{DQO} / \mathrm{m}^{2}$.d. A remoção de matéria orgânica não foi afetada e a nitrificação mostrou-se bastante estável durante todo o período de operação do reator, independentemente do suporte utilizado. À medida que a carga orgânica foi aumentada, observou-se um aumento na espessura do biofilme e na fração de biomassa em suspensão. Notavelmente, a atividade das bactérias nitrificantes em suspensão foi responsável por mais de $40 \%$ da atividade nitrificante total dos reatores. O teor de polissacarídeos e proteínas totais da biomassa aderida aumentou quando o sistema foi submetido ao aumento gradual da DQO.
\end{abstract}

\section{INTRODUÇÃO}

Recentemente, tem se observado um interesse crescente por processos com biofilme para tratamento de águas residuárias. O reator de leito móvel com biofilme (MBBR) é uma tecnologia ambiental em evidência. Os micro-organismos crescem aderidos a materiais plásticos formando filmes microbianos. Esse sistema é favorável para as bactérias cujo crescimento é lento, tais como bactérias nitrificantes, as quais podem ser mantidas no sistema mesmo em condições de alta carga hidráulica e orgânica. Essa última condição favorece o desenvolvimento de micro-organismos heterotróficos de crescimento rápido, podendo ocasionar a redução da atividade nitrificante. A maioria dos trabalhos direcionados ao estudo de sistemas MBBR submetidos a altas cargas orgânicas não avalia o desempenho de nitrificação (Aygun et al., 2008). Além disso, a influência do tipo de material suporte, nessas condições, ainda não foi abordada. O objetivo deste estudo foi avaliar o desempenho de dois MBBR em termos de remoção de DQO e nitrogênio amoniacal, submetidos ao aumento gradual da relação DQO/N. Os reatores foram preenchidos com diferentes tipos de materiais suporte para observar a influência do material no desempenho global do tratamento. 


\section{MATERIAIS E MÉTODOS}

\subsection{Condições Operacionais dos Sistemas MBBR}

Os experimentos foram conduzidos em dois sistemas MBBR de escala laboratorial $\left(\mathrm{MBBR}_{1} \mathrm{e}\right.$ $\mathrm{MBBR}_{2}$ ), ambos com volume de $1 \mathrm{~L}$, mantidos em operação por mais de 400 dias. $\mathrm{MBBR}_{1}$ foi preenchido com suportes do tipo Kaldnes ${ }^{\circledR} \mathrm{K} 1$, cuja área específica para o crescimento do biofilme era de $500 \mathrm{~m}^{2} / \mathrm{m}^{3}$. Por sua vez, o $\mathrm{MBBR}_{2}$ foi preenchido com suportes do tipo Mutag BiochipTM (área específica de $3000 \mathrm{~m}^{2} / \mathrm{m}^{3}$ ).

No intuito de obter a mesma área específica para o desenvolvimento de biofilme em ambos os reatores, a quantidade de material de suporte utilizada correspondeu a uma fração de volume de $50 \%$ e de $8,3 \%\left(\mathrm{~V}_{\text {suporte }} / \mathrm{V}_{\text {reator }}\right)$ para o $\mathrm{MBBR}_{1}$ e $\mathrm{MBBR}_{2}$, respectivamente. Os reatores foram inoculados com lodo ativado proveniente de uma estação de tratamento de esgoto doméstico do município do Rio de Janeiro. A alimentação dos reatores foi a mesma, consistindo de meio sintético contendo acetato de sódio como fonte de carbono orgânico e cloreto de amônio como fonte de nitrogênio. A composição do meio de alimentação está descrita na Tabela 1. Uma solução de micronutrientes foi adicionada em uma proporção de $0,5 \mathrm{~mL}$ para cada litro de meio preparado. $\mathrm{O}$ tempo de retenção hidráulica $(\mathrm{TRH})$ foi fixado em $12 \mathrm{~h}$. Os sistemas MBBR foram submetidos a diferentes razões DQO/N afluente, tal como indicado na Tabela 2.

Tabela 1 - Composição do meio sintético utilizado para alimentação dos reatores.

\begin{tabular}{cc}
\hline Composto & Concentração $(\mathrm{g} / \mathrm{L})$ \\
\cline { 2 - 3 } $\mathrm{KH}_{2} \mathrm{PO}_{4}$ & 0,222 \\
$\mathrm{MgSO}_{4}$ & 0,053 \\
$\mathrm{NaCl}_{2}$ & 0,2225 \\
$\mathrm{NaHCO}_{3}$ & 0,9 \\
$\mathrm{NaAc}_{3} \mathrm{H}_{2} \mathrm{O}^{\mathrm{a}}$ & 1,0284 \\
$\mathrm{NH}_{4} \mathrm{Cl}$ & 0,29 \\
\end{tabular}

Tabela 2 - Condições operacionais dos sistemas de leito móvel com biofilme.

\begin{tabular}{ccccc}
\hline $\begin{array}{c}\text { Regime } \\
\text { operacional }\end{array}$ & $\begin{array}{c}\text { DQO } \\
\text { (mg/trada }\end{array}$ & $\begin{array}{c}\text { Amônia } \\
(\mathrm{mg} / \mathrm{L})\end{array}$ & Razão DQO/N & $\begin{array}{c}\text { Tempo } \\
\text { operacional } \\
\text { (dias) }\end{array}$ \\
\hline 1 & 400 & 100 & 4 & 112 \\
2 & 800 & 100 & 8 & 114 \\
3 & 1200 & 100 & 12 & 144 \\
4 & 1600 & 100 & 16 & $78^{\mathrm{a}}$ \\
\hline
\end{tabular}

${ }^{a}$ Reatores em operação no Regime 4. 


\section{9 a 22 de outubro de 2014 \\ Florianópolis/SC}

Testes adicionais foram realizados para avaliar a atividade nitrificante da biomassa em suspensão e compará-la com a atividade nitrificante total (biomassa em suspensão e aderida). Nos experimentos para avaliar a atividade nitrificante total, um pulso de uma solução concentrada de amônio foi adicionado a cada reator, e a concentração de amônio foi medida ao longo do tempo. Com o objetivo de avaliar somente a atividade nitrificante da biomassa em suspensão, o mesmo teste foi realizado retirando-se todos os suportes de cada reator.

\subsection{Metodologias Analíticas}

Demanda química de oxigênio (DQO) e amônio foram quantificados de acordo com Standard Methods (APHA, 2005). Sólidos aderidos totais (SAT) e sólidos aderidos voláteis (SAV) foram quantificados conforme descrito por Bassin et al. (2012). Teor de polissacarídeos totais foi medido de acordo com Dubois et al. (1956), enquanto que a concentração de proteína total foi determinada pelo ensaio de Bradford (Bradford et al., 1976).

\section{RESULTADOS E DISCUSSÃO}

Com exceção do início da operação (primeiros 40 dias), período no qual os suportes estavam sendo colonizados por micro-organismos (estágio formação do biofilme), a remoção de DQO observada foi superior a $90 \%$ em ambos os sistemas, inclusive na condição de maior carga orgânica superficial (12,8 g DQO/m².d), aplicada no quarto regime de operação (Figura 1a). Durante o período de partida, que se estendeu até o $30^{\circ}$ dia de operação, a remoção de amônio foi ligeiramente superior no reator preenchido com suporte Kaldnes $\mathrm{K} 1\left(\mathrm{MBBR}_{1}\right)$ em comparação com a obtida no reator contendo os suportes Mutag $\left(\mathrm{MBBR}_{2}\right)$. No entanto, a partir do $40^{\circ}$ dia de operação, remoção completa de amônio foi obtida em ambos os reatores (Figura 1b), apesar do aumento gradual da DQO afluente ao longo dos regimes 1 a 4 . Esses resultados indicam que os índices de nitrificação foram mantidos constantes, a despeito do aumento gradual da carga orgânica aplicada. Além disso, os diferentes suportes utilizados em cada sistema não apresentaram influência no desempenho do sistema.

A quantidade de suporte adicionada em cada reator foi escolhida de modo a se obter a mesma área específica teórica para o crescimento do biofilme em ambos os reatores. Diante desse fato, esperava-se que as concentrações de biomassa fossem semelhantes nos dois reatores. Entretanto, a quantidade de biomassa presente no $\mathrm{MBBR}_{1}$ (cerca de $5 \mathrm{gSAV} / \mathrm{L}$, em média) foi cerca de quatro vezes maior do que no $\mathrm{MBBR}_{2}$. Esse resultado sugere que a área específica para a formação do biofilme, comumente fornecida pelos fabricantes dos suportes, deve ser usada com cautela, uma vez que o teor de biomassa em um sistema MBBR não depende apenas da área teórica disponível para deposição de biofilme no suporte, mas também da configuração do suporte. Com base nos experimentos, a configuração do suporte Kaldnes K1 permitiu a obtenção de uma maior quantidade de biomassa no interior do sistema. No entanto, mesmo apresentando menor concentração de sólidos, 
o desempenho do $\mathrm{MBBR}_{2}$ foi similar ao do $\mathrm{MBBR}_{1}$ em termos de remoção de matéria orgânica e amônio.

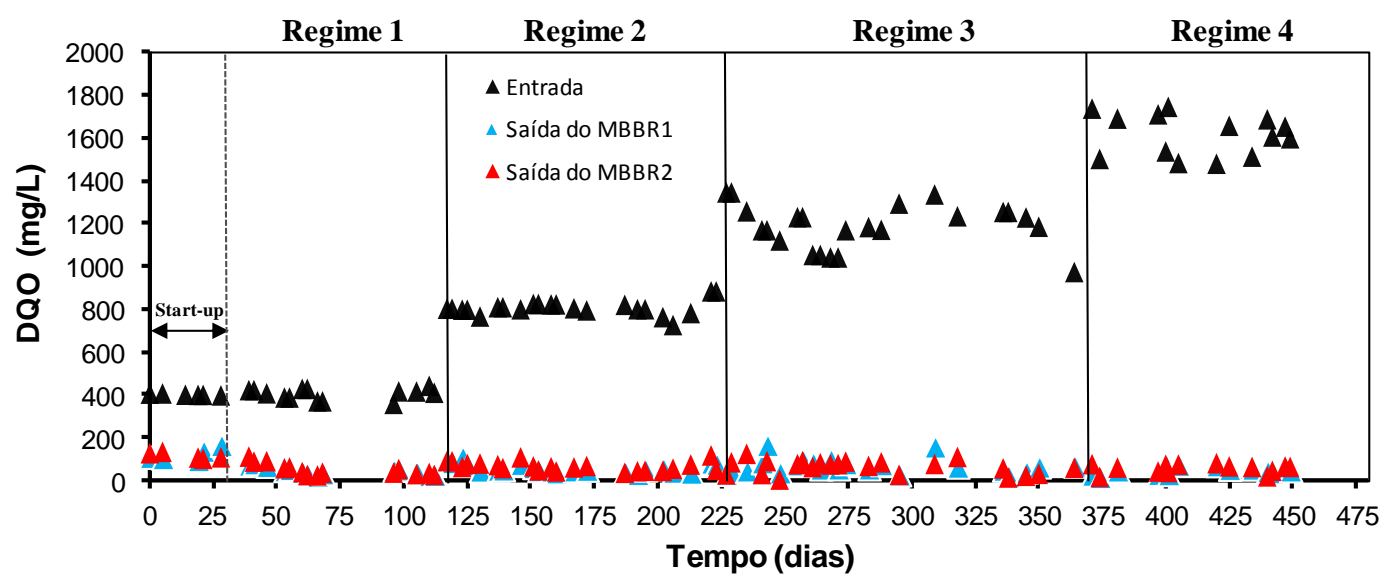

(a)

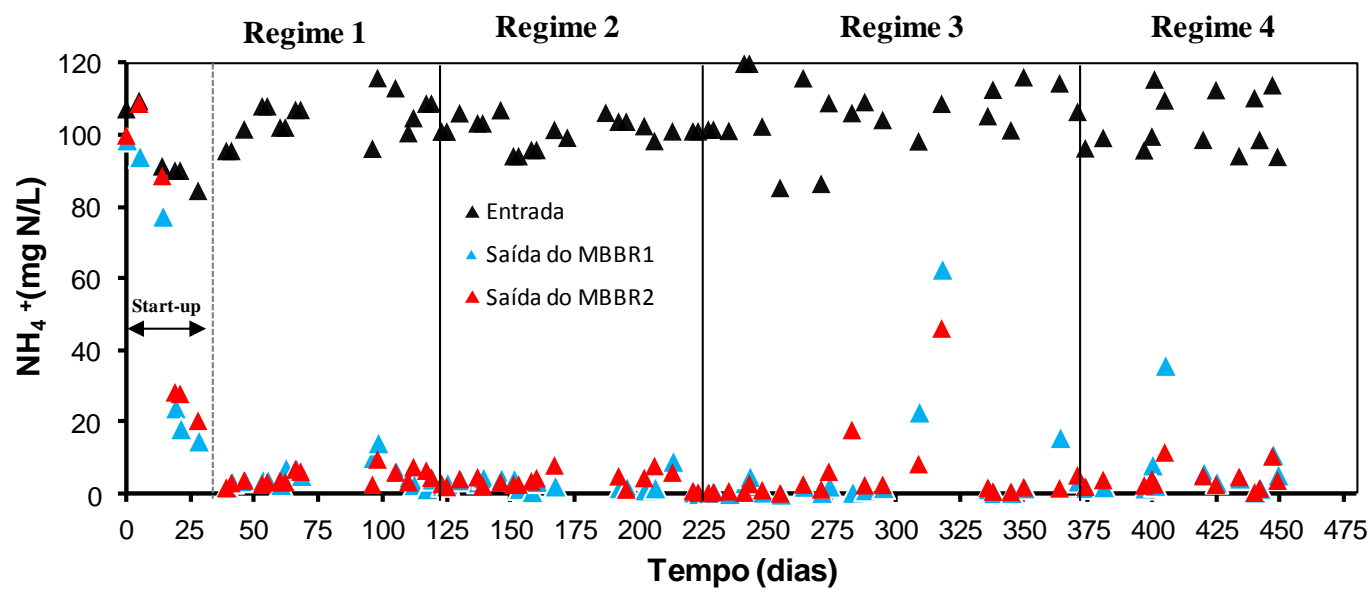

(b)

Figura 1 - Perfis de DQO (a) e amônio (b) obtidos durante todos os regimes operacionais do $\mathrm{MBBR}_{1}$ e $\mathrm{MBBR}_{2}$. A etapa de start-up refere-se ao período de formação do biofilme.

A espessura do biofilme nos dois sistemas foi maior na condição de maior carga orgânica aplicada (regime 4). A Figura 2 ilustra a biomassa imobilizada nos suportes Kaldnes K1 e Mutag Biochip no regime 4. Como pode ser observado, os diferentes suportes estiveram completamente saturados com a biomassa, levando a uma taxa de desprendimento de biofilme mais elevada e aumentando a quantidade de biomassa suspensa. A quantidade de sólidos presentes no efluente aumentou consideravelmente em ambos os reatores com o aumento gradual da DQO ao longo dos 
regimes. A concentração de biomassa suspensa nos reatores no regime 4 foi cerca de 6 vezes maior que no regime 1 para ambos os sistemas MBBR.

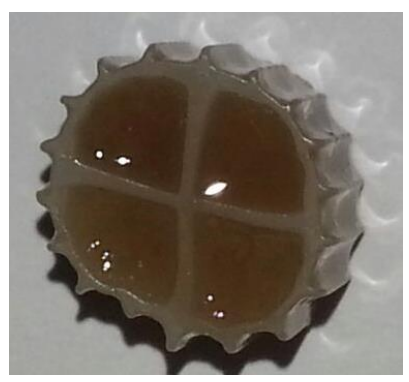

(a)

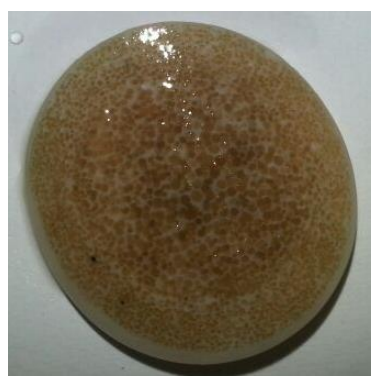

(b)

Figura 2 - Biofilme aderido ao suporte Kaldnes K1 - MBBR 1 (a) e Mutag Biochip - $\mathrm{MBBR}_{2}$ (b) no regime 4.

A atividade das bactérias nitrificantes em suspensão é muitas vezes negligenciada nos estudos que relatam a operação dos sistemas MBBR. De fato, a concentração de biomassa suspensa é reduzida nesses sistemas, os quais geralmente são operados em baixos TRH. Nessas condições, pouca biomassa suspensa é mantida. Nesse trabalho, no entanto, o TRH de $12 \mathrm{~h}$ imposto aos reatores juntamente com as altas cargas orgânicas aplicadas possibilitaram a manutenção de quantidade significativa de biomassa em suspensão, oriunda do desprendimento do biofilme. Nesse contexto, avaliou-se a atividade nitrificante da biomassa suspensa em experimentos nos quais todos os suportes foram retirados do sistema.

Foi observado que a atividade de nitrificação da biomassa em suspensão correspondeu a índices superiores a $50 \%$ da atividade nitrificante total (biomassa suspensa + biofilme) em ambos os reatores nos regimes 3 e 4 . Esse resultado evidencia a importância de se levar em conta a fração de biomassa em suspensão para se estimar a capacidade de tratamento do biorreator, especialmente quando a taxa de desprendimento do biofilme é elevada.

As concentrações de polissacarídeos (PS) e proteínas (PT) totais no biofilme do $\mathrm{MBBR}_{1}$ foram maiores do que no $\mathrm{MBBR}_{2}$. Este resultado, em particular, está diretamente relacionado com a maior concentração de biomassa encontrado no primeiro reator. No $\mathrm{MBBR}_{1}$, preenchido com o suporte Kaldnes K1, as concentrações de PS e PT observadas aumentaram substancialmente com o aumento da carga orgânica. Por outro lado, no $\mathrm{MBBR}_{2}$, as concentrações de PS e PT não variaram muito. 


\section{CONCLUSÕES}

Dois sistemas MBBR preenchidos com diferentes materiais suporte foram submetidos ao aumento gradual da carga orgânica. $\mathrm{O}$ desempenho de ambos os sistemas no que tange à remoção de matéria orgânica e nitrificação foi muito satisfatório, independentemente do material suporte utilizado. Foi evidenciado que o percentual de nitrificação obtido por meio da fração de biomassa suspensa pode ser relevante em sistemas MBBR, especialmente nos casos em que ocorrer desprendimento significativo do biofilme.

\section{REFERÊNCIAS}

APHA, AWWA, WEF. Standard Methods for the Examination of Water and Wastewater, 21th edition, American Public Health Association, American Water Works Association, Water Pollution Control Federation, Washington DC, USA, 2005.

AYGUN, A.; NAS, B.; BERKTAY, A. Influence of high organic loading rates on COD removal and sludge production in moving bed biofilm reactor. Environ. Sci., v. 25(9), pp.1311-1316, 2008.

BASSIN, J. P.; KLEEREBEZEM, R.; ROSADO, A. S.. VAN LOOSDRECHT, M. C. M.; DEZOTTI, M. Effect of different operational conditions on biofilm development, nitrification, and nitrifying microbial population in moving-bed biofilm reactors. Environ. Sci. Technol., v. 46(3), pp. 1546-1555, 2012.

BRADFORD, M. M. Rapid and sensitive method for the quantitation of microgram quantities of protein utilizing the principle of protein-dye binding, Anal. Biochem. v. 72(1-2), pp. 248-254, 1976.

DUBOIS, M.; GILLES, K. A.; HAMILTON, J. K.; REBERS, P. A.; SMITH, F. Colorimetric method for determination of sugars and related substances. Anal. Chem. v. 28(3), pp.350-356, 1956. 